\title{
The prevalence of metabolic syndrome among low-income South Asian Americans
}

\author{
Saira A Khan* and Robert T Jackson \\ Department of Nutrition and Food Science, University of Maryland, 0119 Skinner Building, College Park, \\ MD 20740, USA
}

Submitted 25 February 2014: Final revision received 26 February 2015: Accepted 6 March 2015: First published online 11 May 2015

\begin{abstract}
Objective: The purpose of the present paper is to examine the prevalence of metabolic syndrome (MetS) and its components using the harmonized definition in an interviewed sub-sample of diverse, low-income, adult South Asians (SA) of both sexes residing in Maryland. We also wanted to derive a BMI cut-off value that was highly correlated with the recommended waist circumference (WC) that we could apply to a larger sample of SA Americans for whom only BMI values were available from clinic files. We also examined differences in MetS prevalence among various Asian ethnic groups (defined by country of origin) and the clustering pattern of their MetS components.

Design: Clinical data extraction on subjects ( $n$ 1002) and interviewees ( $n$ 401) were used in a cross-sectional study of SA Americans.

Setting: Two community health centres in Montgomery and Baltimore County, MD, USA.

Subjects: SA adult males and females ( $n$ 1403) aged 20-68 years.

Results: The prevalence of MetS using harmonized WC cut-offs $(90 \mathrm{~cm}$ in men and $80 \mathrm{~cm}$ in women) was $47 \%$ in men and $54 \%$ in women. Using a BMI of $23.0 \mathrm{~kg} / \mathrm{m}^{2}$ gave a similar prevalence of MetS for males (48\%) and females (47\%). Of the five MetS components, the prevalence pattern differed among the ethnic groups, particularly for SA Indians.

Conclusions: The prevalence of MetS in a diverse, low-income, SA American immigrant group using the harmonized definition was $51 \%$. Derived lowered BMI cut-off of $23.0 \mathrm{~kg} / \mathrm{m}^{2}$ should be used by clinicians in studies on SA when WC values are not available for detecting metabolic risk. SA Indians had a higher prevalence of abnormal TAG and blood glucose values compared with other SA, and therefore results for SA Indians should not be generalized to all SA ethnic groups.
\end{abstract}

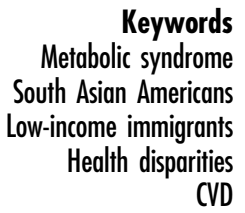

CVD
CVD and type 2 diabetes are leading causes of death in the USA. Studies show that metabolic syndrome (MetS) is an important determinant of cardiovascular risk and other related $\mathrm{CVD}^{(1,2)}$. In the USA, South Asian(s) (SA) are one of the fastest-growing minorities ${ }^{(2)}$; however, very little is known about the prevalence of MetS and its metabolic profile in a diverse group of low-income SA Americans ${ }^{(3)}$. MetS studies of SA in the Asian subcontinent have shown increased prevalence compared with Americans ${ }^{(4,5)}$. In the USA, low-income SA populations have a greater prevalence of obesity and related diseases ${ }^{(6,7)}$, have less access to healthful foods, less physical activity outlets and generally less knowledge related to health management ${ }^{(4,5)}$. Physiological and metabolic markers of low-income immigrant populations associated with MetS can be assessed in community health clinics.
Accurate assessment of MetS and its components, particularly obesity ${ }^{(8,9)}$, has been important in identifying individuals at greater risk for chronic disease and can be important to individuals who may not be able to afford regular preventive health care ${ }^{(5)}$.

MetS is a clustering of atherogenic metabolic abnormalities with different definitions ${ }^{(1,9-11)}$. Recently, several major organizations developed a consensus definition of MetS. This new, harmonized definition (2009) requires the presence of three or more of the following five components: (i) abdominal obesity as measured by waist circumference (WC); (ii) elevated TAG; (iii) low HDLcholesterol (HDLC); (iv) elevated blood pressure; and (v) elevated fasting blood glucose ${ }^{(1)}$.

There has been continued effort to improve the definition for MetS as well as its clinical detection. There is still 
debate about the clinical usefulness of some components in $\mathrm{SA}^{(10,11)}$. However, abdominal obesity (WC) is now the recommended anthropometric measure for MetS because it has been shown to be more important in the development of CVD-related illnesses ${ }^{(1)}$. WC has rarely been measured in the clinic environment in the past compared with BMI. Much controversy exists, particularly in SA, related to the accuracy of the obesity cut-offs (WC and BMI) for elevated risk and the appropriate cut-off values to use. This discussion has been particularly relevant for SA groups since Asians tend to have a higher percentage of body fatness at lower BMI and WC values ${ }^{(12-16)}$, therefore facing elevated risk at WC and BMI values below established European-derived cut-off values.

More is known about MetS in SA residing in Asia and Europe than is known about immigrant SA residing in the USA. Furthermore, although the prevalence of MetS has been reported in previous population studies of Asian Indians $^{(17,18)}$, few studies exist, in the USA, on MetS in SA from countries other than India, such as Pakistan, Bangladesh, Sri Lanka, Iran, Afghanistan, Bhutan and Nepal, all of which make up the SA region. Moreover, the clustering of MetS indicators has not been studied among the broader grouping of SA in the USA. Finally, the studies we do have on SA Indians mentioned previously ${ }^{(16)}$ are not recent and have mostly used definitions of MetS that are no longer recommended.

The purpose of the present research is to examine the prevalence of MetS and its abnormal indicators in and among an ethnically diverse sample of low-income adult SA of both sexes residing in Maryland. We also want to develop and suggest an appropriate BMI cut-off that captures a similar prevalence of MetS to that recommended for SA by the current consensus definition.

\section{Experimental methods}

\section{Subjects}

The total sample consisted of 1403 apparently healthy SA men and women aged between 20 and 68 years whose countries of birth were Pakistan, India, Bangladesh, Sri Lanka, Iran, Afghanistan, Bhutan and/or Nepal. The sample was obtained from two religious community medical centres in Montgomery and Baltimore Counties in the State of Maryland between May 2012 and June 2013. The two centres, in addition to acting as a focal point for social and religious activities of the mostly Muslim community, also provided free primary medical care for low-income and indigent members of the community. Individuals who were pregnant and those with other metabolic diseases (cancer, CVD, type 1 diabetes, HIV) were excluded. From the clinical file extraction (CFE), we excluded individuals sampled from the clinical files with incomplete data such as date of birth, ethnicity and variables needed to calculate MetS.
Our research consisted of two databases that totalled 1403 subjects. The first sample included a CFE ( $n$ 1002) and the second interviewees ( $n$ 401), as described below.

Our goal was to determine the BMI cut-off value (from the interviewees) that would be comparable to that calculated by the suggested harmonized definition $^{(1)}$. First, the prevalence of MetS was calculated using the harmonized definition in the sub-sample ( $n$ 401). Next, we wanted to test the validity of these WC cut-offs in the sub-sample ( $n$ 401). In order to derive the WC values we performed receiver-operating characteristic (ROC) curve analysis and used established procedures described below to determine the optimal WC cut-off values. ROC curve and correlation analyses, performed on the interviewed sample, revealed that the harmonized WC cut-offs ( $\geq 90 \mathrm{~cm}$ in males, $\geq 80 \mathrm{~cm}$ in females) were appropriate. Next, we determined which BMI cut-off gave a comparable prevalence of MetS to the recommended WC cut-offs $^{(1)}$ using several BMI cut-off values previously suggested for SA (e.g. $23.0 \mathrm{~kg} / \mathrm{m}^{2(13)}, 25 \cdot 0 \mathrm{~kg} / \mathrm{m}^{2(19,20)}$, $\left.30 \cdot 0 \mathrm{~kg} / \mathrm{m}^{2(19,21)}\right)$. Some of these BMI values were derived from ROC curve analysis ${ }^{(8,22)}$.

The BMI of $23.0 \mathrm{~kg} / \mathrm{m}^{2}$ was found to be a good substitute for the harmonized WC cut-off value, yielding a similar percentage of MetS. Thus, the cut-off of $23.0 \mathrm{~kg} / \mathrm{m}^{2}$ was then used to study MetS prevalence in the second sample of 1002 subjects for whom WC was not available in their clinic records and on the combined sample of 1403 subjects.

\section{Interviewed sample}

A convenience sample of 401 consecutive walk-ins was interviewed in their native language by one of us. Sample size was determined by performing a power calculation based on MetS prevalence from previous SA studies in the $\mathrm{USA}^{(23,24)}(27 \%)$. This calculation resulted in a sample size of 400 with a reasonable minimum effect of $\alpha=0.05$, a minimum power to detect that effect, and the sample size that would achieve that desired level of power was $80 \%$.

All walk-in patients consented for interviews. Medical and chronic disease history, smoking, alcohol consumption, income categories (\$US 0-15 000, \$US 16 000-30 000, \$US 31 000-45000), highest education completed (none, junior high, high school, bachelor, graduate), sociodemographic data (age, country of origin, smoking, physical activity, total years in the USA) and the reason for clinic attendance were obtained. Physical activity was defined as activities above and beyond daily living (cleaning, cooking and household chores), measured by four questions: (i) 'Do you engage in vigorous exercise?', (ii) 'How many days a week?', (iii) 'How many minutes a day?' and (iv) 'What exercise do you engage in?' where $1=$ walking, 2 = running, 3 =jogging, $4=$ weight, $5=$ stretch, $6=$ other. Weight, height and WC were obtained on these individuals. Their weight and height 
were measured on a Detecto Promed 6129 scale (Toldedo, OH, USA) with subjects wearing light street clothing with shoes removed. Weight was measured to the nearest $0.1 \mathrm{~kg}$ and height to the nearest $0.1 \mathrm{~cm}$. Subjects removed hair ornaments and buns from the top of the head in order to measure stature. BMI was calculated as (weight in $\mathrm{kg}$ )/(height in metres) ${ }^{2}$. WC was measured at the midpoint point between the iliac crest and lower rib to the nearest $0 \cdot 1 \mathrm{~cm}$. The cut-off values for WC were $\geq 90 \mathrm{~cm}$ in males, $\geq 80 \mathrm{~cm}$ in females ${ }^{(6)}$.

Information on the remaining MetS indicators were obtained from the clinic charts of these 401 subjects. The laboratory values were analysed by Lab Corp. (Burlington, NC, USA).

\section{Assessment of metabolic syndrome from interviews}

The diagnosis of MetS was based on the harmonized definition $^{(9)}$ which required the presence of three or more of the following five components: (i) abdominal obesity (WC cut-offs for SA: men $\geq 90 \mathrm{~cm}$, women $\geq 80 \mathrm{~cm}$ ); (ii) elevated TAG ( $\geq 150 \mathrm{mg} / \mathrm{dl}$ or statins use); (iii) low HDLC $(<40 \mathrm{mg} / \mathrm{dl}$ in men, $<50 \mathrm{mg} / \mathrm{dl}$ in women or use of medication); (iv) elevated blood pressure (systolic/ diastolic $\geq 130 / 85 \mathrm{mmHg}$ or use of antihypertensive medication); and (v) elevated fasting glucose (>100 mg/dl or use of hypoglycaemic agents).

\section{Clinical files}

A systematic sample of clinic records of SA American subjects was obtained using the following formula: $K \leq N / n$. From a random start we selected every second file until the target sample size ( $n$ 1002) was reached. For all subjects (both interviewed and clinic charts) we obtained standard background information including socio-economic (income, education), sociodemographic (age, ethnicity) and medical history (family background of disease, smoking, etc.).

\section{Assessment of metabolic syndrome from clinical file extraction}

The diagnosis of MetS for interviewees was based on the harmonized definition ${ }^{(9)}$ which required the presence of three or more of the five components, as described above. However, for the 1002 clinical files, we used a modified harmonized definition (employing a BMI of $23.0 \mathrm{~kg} / \mathrm{m}^{2}$ instead of WC, which was not present in clinic files). BMI $\left(\mathrm{kg} / \mathrm{m}^{2}\right)$ was categorized as: underweight $(\mathrm{BMI}<18.5$ $\left.\mathrm{kg} / \mathrm{m}^{2}\right)$, normal $\left(18.5 \mathrm{~kg} / \mathrm{m}^{2} \leq \mathrm{BMI}<22.9 \mathrm{~kg} / \mathrm{m}^{2}\right)$, overweight $\left(23.0 \mathrm{~kg} / \mathrm{m}^{2} \leq \mathrm{BMI}<24.9 \mathrm{~kg} / \mathrm{m}^{2}\right)$ and obese (BMI $\geq$ $\left.25 \cdot 0 \mathrm{~kg} / \mathrm{m}^{2}\right)$ as recommended by $\mathrm{WHO}^{(13,25)}$ for SA.

The prevalence of each abnormal component of the MetS was measured individually and in combinations of two, three and four for the entire sample ( $n$ 1403) and for the larger ethnic group categories (i.e. Indians, Pakistanis and Bengalis).

\section{Statistical analysis}

All data were analysed using the SAS statistical software package version 9.2. Results were expressed as means and their standard errors or as numbers and percentages. Student's $t$ test was used to compare means between groups and the $\chi^{2}$ test to compare proportions between groups. We used ANOVA to compare the characteristics of MetS indicators among groups. ROC curve analyses were used ( $n$ 401) to determine the appropriate sex-specific WC cut-offs for MetS and to compare the sensitivity and specificity of BMI and WC cut-off values. We used two or more risk factors from the harmonized definition (in addition to WC or BMI cut-off) to define MetS, including hypertriacylglycerolaemia, hyperglycaemia, hypertension and low HDLC. Using logistic regression analysis and plotting sensitivity $v$. 1 -specificity, we investigated which WC cut-off value best predicted MetS using two or more abnormal MetS indicators. Perfect prediction using WC would have a point on the ROC curve with $100 \%$ sensitivity and specificity. The distance on the ROC curve from perfect prediction was calculated for WC values. To determine the optimal thresholds, the point on the ROC curve with maximum Youden index (sensitivity-(1-specificity)), and the point with shortest distance value from the point $(0,1)$ $\left(d=\sqrt{(1-\text { sensitivity })^{2}+(1-\text { specificity })^{2}}\right)$, were calculated $^{(22)}$. These are the two most commonly used methods for establishing the optimal cut-offs ${ }^{(22)}, P \leq 0.05$ was considered statistically significant.

For the interviewees ( $n$ 401), we performed a logistic regression to evaluate the associations between those with and without MetS and exercise, years in the USA, years in school, income and country of origin. Age and sex were covariates.

All interviewees gave informed consent before participating in the study. The study protocol for all subjects was approved by both the Institutional Review Board of University of Maryland and the review boards of the two community centres.

\section{Results}

The sample consisted of a total of 1403 low-income, uninsured SA immigrants to the USA who utilized two community health centres in Montgomery and Baltimore Counties in the State of Maryland. Data were collected on 1002 subjects from the clinical files and an additional 401 subjects were separately interviewed. Both samples were similar in terms of mean age, ethnic breakdown, education within ethnic groups, mean income and mean years of residence in the USA. Forty-seven per cent of the total sample was male ( $n$ 661) and $53 \%$ was female $(n 742)$. The sample included individuals from: India $18 \%$, Pakistan 53\%, Bangladesh $16 \%$, Nepal 4\%, Sri Lanka 2\%, Afghanistan $2 \%$, Iran 3\% and Bhutan 1\%. We divided the 
sample into four subgroups: Pakistanis, Indians, Bengalis and, due to small sample sizes, the remaining nationalities into a category called 'Other SA' (Table 1). The mean height, weight and BMI are presented in Table 1 . Overall, $71 \%$ of the subjects were overweight and obese. Normal-weight subjects comprised $27 \%$ of the sample, while $40 \%$ were overweight, $31 \%$ were obese and $<1 \%$ were underweight (BMI $\leq 18.5$ $\mathrm{kg} / \mathrm{m}^{2}$ ). Underweight subjects ( $n$ 10) were not analysed.

A majority of the subjects in all ethnic groups were married and/or living with a partner. Education status varied significantly by sex; $20 \%$ of females had no education compared with only $7 \%$ of males. Bengali subjects had the lowest education level (18.3\% were educated to the 5 th grade level), while Indians were the most educated (22\% at the graduate level). Males also had a higher mean number of years in school (13 (sE 4) years) compared with females (11 (se 5) years; $P<0 \cdot 05$ ). The majority of the sample reported an income of \$US 30000 or less for a family of four. More than half of the subjects reported being employed (53\%), while $47 \%$ were unemployed. The mean number of years residing in the USA was 11 (SE 9) years. The mean length of residence in the USA was significantly longer $(P<0.05)$ for males (12 (SE 9) years) compared with females (10 (sE 9) years; $P<0 \cdot 05$ ). Nearly
$80 \%$ of the sample was Muslim and the remainder were Christian, Hindu, Sikh and Buddhist. The subjects spoke seventeen different languages. The predominant languages spoken were Urdu, Panjabi and Bengali. Smoking was reported by $2 \%$ of the sample ( $n$ 28) and was more common in males than females. Table 1 shows the mean lipid and blood pressure values for the entire sample. In our interviewed sample, the ethnic differences defined by the country of origin showed that, overall, Indians had the highest prevalence of MetS (55\%) compared with Bengalis (51\%), Pakistanis (49\%) and Other SA (44\%).

\section{Prevalence of metabolic syndrome in the interviewed sub-sample}

The sub-sample of interviewed subjects ( $n$ 401) included 190 males and 211 females. They exercised on average for two days out of the week for about $22 \mathrm{~min} / \mathrm{d}$. The mean WC was not statistically different between males (97 $(\mathrm{se} 12) \mathrm{cm})$ and females $(96(\mathrm{se} \mathrm{13)} \mathrm{cm})$. More females had abnormal WC values (57\%) compared with males (43\%). Subjects were asked the reason for their visit and they reported the following (from most to least prevalent): for colds and flu (46\%), follow-up visits to receive pain medication (27\%), regular annual visit for women (18\%)

Table 1 Demographic and clinical characteristics by sex among South Asian American adults aged 20-68 years from two community health centres in Montgomery and Baltimore County, MD, USA, May 2012-June 2013

\begin{tabular}{|c|c|c|c|c|c|c|}
\hline & \multicolumn{2}{|c|}{ Overall } & \multicolumn{2}{|c|}{ Males ( $n$ 661) } & \multicolumn{2}{|c|}{ Females ( $n$ 742) } \\
\hline & Mean & SE & Mean & SE & Mean & SE \\
\hline \multicolumn{7}{|l|}{ Characteristic } \\
\hline Age (years) & 48 & 11 & 48 & 11 & 48 & 12 \\
\hline Height $(\mathrm{cm})$ & 164 & 3 & $170^{\star *}$ & 3 & 157 & 3 \\
\hline Weight (kg) & 74 & 30 & $79^{\star \star}$ & 33 & 69 & 32 \\
\hline $\operatorname{BMI}\left(\mathrm{kg} / \mathrm{m}^{2}\right)$ & 28 & 5 & $24^{\star \star}$ & 5 & 28 & 6 \\
\hline WC (cm) (n 401) & 96 & 12 & 97 & 12 & 96 & 13 \\
\hline Years in USA ( $n$ 401) & 11 & 9 & $12^{*}$ & 9 & 10 & 9 \\
\hline Days of exercise/week ( $n$ 401) & 2 & 2 & 2 & 2 & 2 & 3 \\
\hline \multicolumn{7}{|l|}{ Clinical variables } \\
\hline HDLC (mg/dl) & 46 & 13 & $42^{\star \star}$ & 11 & 49 & 14 \\
\hline TAG (mg/dl) & 160 & 110 & $180^{\star \star}$ & 130 & 141 & 85 \\
\hline Blood glucose (mg/dl) & 113 & 52 & $119^{\star *}$ & 63 & 108 & 39 \\
\hline Systolic BP (mmHg) & 124 & 20 & $125^{\star \star}$ & 17 & 123 & 20 \\
\hline \multirow[t]{2}{*}{ Diastolic BP (mmHg) } & 77 & 11 & $79^{\star \star}$ & 11 & 76 & 12 \\
\hline & $\%$ & $n$ & $\%$ & $n$ & $\%$ & $n$ \\
\hline \multicolumn{7}{|l|}{ Ethnic origin } \\
\hline Pakistan (\%) & 53 & 761 & 56 & 373 & 52 & 388 \\
\hline India (\%) & 18 & 245 & 17 & 110 & 18 & 135 \\
\hline Bangladesh (\%) & 16 & 224 & 17 & 110 & 15 & 114 \\
\hline Other SA† (\%) & 12 & 171 & 10 & 68 & 14 & 103 \\
\hline Married & 78 & 1032 & 47 & 488 & 53 & 544 \\
\hline \multicolumn{7}{|l|}{ Education } \\
\hline None (\%) & 13 & 141 & 19 & 27 & 81 & 114 \\
\hline Elementary (\%) & 10 & 104 & 27 & 28 & 73 & 76 \\
\hline High school (\%) & 39 & 417 & 48 & 199 & 52 & 218 \\
\hline Bachelor (\%) & 25 & 265 & 59 & 157 & 41 & 108 \\
\hline Graduate (\%) & 11 & 121 & 63 & 76 & 37 & 45 \\
\hline
\end{tabular}

WC, waist circumference; HDLC, HDL-cholesterol; BP, blood pressure.

Mean value was significantly different from that of females: ${ }^{*} P<0.05,{ }^{* \star} P<0.001$.

†'Other SA' comprise individuals from Sri Lanka, Nepal, Iran, Afghanistan and Bhutan. 
Table 2 Prevalence of metabolic syndrome, comparing BMI and WC cut-offs by sex, among South Asian American adults aged 20-68 years from two community health centres in Montgomery and Baltimore County, MD, USA, May 2012-June 2013

\begin{tabular}{|c|c|c|c|c|}
\hline & \multicolumn{2}{|c|}{$\mathrm{BMI} \geq 23.0 \mathrm{~kg} / \mathrm{m}^{2} \dagger(n 1403)$} & \multicolumn{2}{|c|}{$W C \geq 80 \mathrm{~cm}$ (male),$\geq 90 \mathrm{~cm}$ (female) $\ddagger(n$ 401) } \\
\hline & $\%$ & $n$ & $\%$ & $n$ \\
\hline Total males $(n 661)$ & 48 & 317 & 46 & 88 \\
\hline Pakistani & 50 & 188 & 49 & 54 \\
\hline Indian & 47 & 53 & 46 & 16 \\
\hline Bengali & 45 & 49 & 50 & 14 \\
\hline Other SA§ & 40 & 27 & 25 & 4 \\
\hline Total females ( $n$ 742) & 47 & 349 & 54 & 113 \\
\hline Pakistani & 49 & 189 & 49 & 58 \\
\hline Indian & 45 & 65 & 62 & 26 \\
\hline Bengali & 53 & 52 & 52 & 16 \\
\hline Other SA§ & 37 & 43 & 56 & 13 \\
\hline Overall ( $n$ 1403) & 47 & 659 & 51 & 206 \\
\hline
\end{tabular}

WC, waist circumference.

+WHO recommendation for South Asians ${ }^{(25)}$.

$\neq$ Consensus harmonized definition for South Asians ${ }^{(1)}$

§'Other SA' comprise individuals from Sri Lanka, Nepal, Iran, Afghanistan and Bhutan.

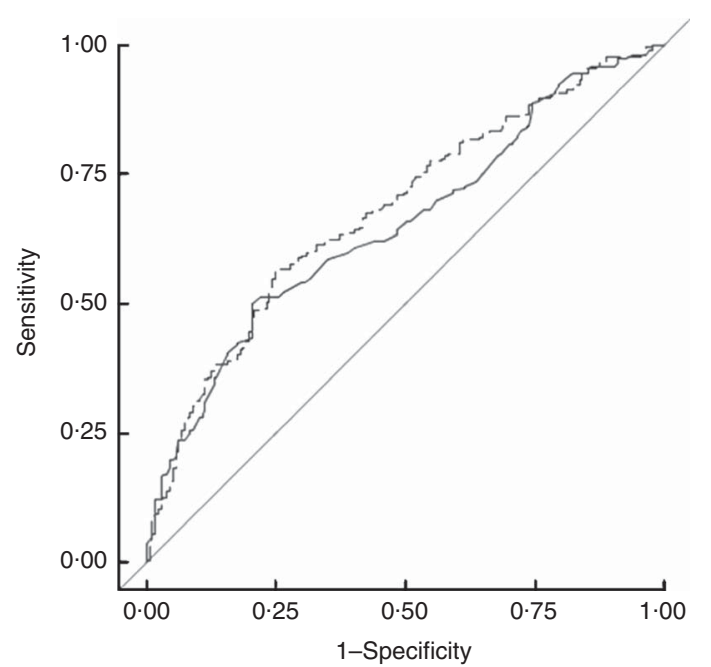

Fig. 1 Comparison of harmonized WC cut-offs $(\geq 90 \mathrm{~cm}$ in males, $\geq 80 \mathrm{~cm}$ in females $\left.{ }^{(1)} ;-, \quad A \cup C=0.6518\right)$ and $B M I$ $\left(\geq 23.0 \mathrm{~kg} / \mathrm{m}^{2(13)} ;---, A U C=0.6796\right)$ in predicting prevalence of metabolic syndrome in 1403 South Asian American adult males and females aged 20-68 years from two community health centres in Montgomery and Baltimore County, MD, USA, May 2012-June 2013 (WC, waist circumference; AUC, area under the ROC curve; ROC, receiver-operating characteristic)

and check-up for an existing condition not related to MetS (9\%). Two females refused to participate in our study due to a lack of time for the survey; therefore, selection bias was unlikely. These females were not significantly different from the other subjects and their refusal did not affect our results.

MetS prevalence using the consensus harmonized definition (WC cut-off value of $\geq 90 \mathrm{~cm}$ in males and $\geq 80 \mathrm{~cm}$ for females) was $46 \%$ for males and $54 \%$ for females (Table 2).

\section{Receiver-operating characteristic curve analysis}

Given that the suggested harmonized ethnic-specific WC cut-off for SA was developed mainly using samples of Asian
Indians, we examined the applicability of these standards to our more diverse sample of SA using a ROC curve analysis. BMI and WC had similar abilities to predict MetS (Fig. 1).

A separate ROC curve analyses indicated that a WC (and two additional abnormal indicators) value of $89 \mathrm{~cm}$ for men and $79 \mathrm{~cm}$ for women optimally predicted MetS in SA Americans (Table 3). Using these cut-offs, there would be a slight, but non-significant, increase in the prevalence of central obesity and in the age-adjusted prevalence of MetS for males compared with that measured by the harmonized MetS definition. Our results were thus similar to confirming the utility of the harmonized recommendation of $90 \mathrm{~cm}$ for males and $80 \mathrm{~cm}$ for females.

\section{Prevalence of metabolic syndrome in the clinical file extraction sample}

Subjects from the clinic files ( $n$ 1002) included 511 males and 491 females. Their mean age (49 years in males, 47 years in females), income (98\% of sample below the federal poverty line) and education (12 years) were similar to those of the interviewed sample. The percentage of abnormal indicators was similar in the CFE sample compared with the interviewed sample; for example, the prevalence of abnormal HDLC was $46 \%$ and $44 \%$, respectively. The prevalence of MetS for the CFE sample ( $n$ 1002) using a modified BMI $\left(23.0 \mathrm{~kg} / \mathrm{m}^{2}\right)$ definition was similar in males and females ( $49 \%$ and $47 \%$, respectively) to that found in the interviewees ( $46 \%$ in males and $54 \%$ in females).

Because the prevalence of MetS was similar in the CFE sample and the interviewees, we decided to combine them ( $n$ 1403) to calculate the sex-specific prevalence of MetS, $48 \%$ in males and $47 \%$ in females.

Prevalence of metabolic syndrome by ethnic group The prevalence of MetS differed by ethnicity, obesity measures (BMI and WC), obesity cut-offs and sex 
Table 3 Sensitivity, specificity, AUC and distance in the ROC curve for WC cut-off values, by sex, among South Asian American adults aged 20-68 years from two community health centres in Montgomery and Baltimore County, MD, USA, May 2012-June 2013

\begin{tabular}{|c|c|c|c|c|}
\hline \multicolumn{5}{|c|}{ Two or more metabolic risk factors } \\
\hline WC cut-off (cm) & Sensitivity (\%) & Specificity (\%) & AUC & Distance in ROC curve \\
\hline \multicolumn{5}{|l|}{ Males } \\
\hline 85 & $80 \cdot 1$ & $28 \cdot 3$ & 0.5692 & 0.58 \\
\hline 86 & $81 \cdot 1$ & $28 \cdot 4$ & 0.5680 & 0.56 \\
\hline 87 & $82 \cdot 2$ & 28.7 & 0.5666 & 0.56 \\
\hline 88 & $82 \cdot 4$ & $28 \cdot 7$ & 0.5652 & 0.54 \\
\hline 89 & $82 \cdot 4$ & 29.2 & 0.5602 & 0.53 \\
\hline 90 & $81 \cdot 8$ & 29.0 & 0.5659 & 0.55 \\
\hline 91 & 81.5 & 28.9 & 0.5690 & 0.57 \\
\hline 92 & $81 \cdot 1$ & 28.8 & 0.5692 & 0.58 \\
\hline 93 & $80 \cdot 9$ & 28.9 & 0.5695 & 0.58 \\
\hline 94 & $80 \cdot 9$ & 28.5 & 0.5695 & 0.60 \\
\hline 95 & $80 \cdot 3$ & $28 \cdot 4$ & 0.5699 & 0.60 \\
\hline \multicolumn{5}{|l|}{ Females } \\
\hline 75 & $85 \cdot 3$ & 28.4 & 0.5688 & 0.59 \\
\hline 76 & $85 \cdot 3$ & $28 \cdot 3$ & 0.5680 & 0.57 \\
\hline 77 & $85 \cdot 3$ & 28.3 & 0.5680 & 0.55 \\
\hline 78 & $85 \cdot 3$ & 28.0 & 0.5664 & 0.55 \\
\hline 79 & $86 \cdot 2$ & $26 \cdot 8$ & 0.5702 & 0.53 \\
\hline 80 & $86 \cdot 2$ & $27 \cdot 5$ & 0.5686 & 0.54 \\
\hline 81 & $86 \cdot 2$ & $27 \cdot 0$ & 0.5663 & 0.54 \\
\hline 82 & $86 \cdot 2$ & $26 \cdot 7$ & 0.5647 & 0.57 \\
\hline 83 & $87 \cdot 2$ & $26 \cdot 4$ & 0.5677 & 0.58 \\
\hline 84 & $88 \cdot 1$ & $26 \cdot 4$ & 0.5723 & 0.59 \\
\hline 85 & 89.0 & $26 \cdot 1$ & 0.5753 & 0.61 \\
\hline 86 & 89.0 & $25 \cdot 8$ & 0.5737 & 0.62 \\
\hline 87 & 89.0 & $25 \cdot 1$ & 0.5705 & 0.62 \\
\hline 88 & 89.0 & 24.6 & 0.5682 & 0.63 \\
\hline
\end{tabular}

AUC, area under the ROC curve; ROC, receiver-operating characteristic; WC, waist circumference.

†Metabolic risk factors were defined according to the International Diabetes Federation harmonized definition: elevated TAG, $\geq 150$ mg/dl or treatment for hypertriacylglycerolaemia; reduced $\mathrm{HDL}$-cholesterol, $<40 \mathrm{mg} / \mathrm{dl}$ for men and $<50 \mathrm{mg} / \mathrm{dl}$ for women or treatment for this lipid abnormality; elevated blood pressure, $\geq 130 \mathrm{mmHg}$ systolic and/or $\geq 85 \mathrm{mmHg}$ diastolic or treatment for previously diagnosed hypertension; elevated fasting plasma glucose, $\geq 100 \mathrm{mg} / \mathrm{dl}$ or previously diagnosed type 2 diabetes $^{(1)}$.

(Table 2). In Pakistani males, the prevalence of MetS using WC ( $\geq 90 \mathrm{~cm})$ was $49 \%$ and BMI $\left(\geq 23 \cdot 0 \mathrm{~kg} / \mathrm{m}^{2}\right)$ was $50 \%$. In Pakistani females, the prevalence of MetS using WC $(\geq 80 \mathrm{~cm})$ was $49 \%$ and using BMI $\left(\geq 23.0 \mathrm{~kg} / \mathrm{m}^{2}\right)$ was $49 \%$. Indian females had the highest prevalence of MetS (62\%) using the harmonized WC measure (Table 2). Bengali males had the highest prevalence of MetS (50\%) using the harmonized WC measure. The prevalence of MetS in the aggregated 'Other SA' males using the harmonized WC ( $\geq 80 \mathrm{~cm}$ ) was $25 \%$, and for Other SA females was $56 \%$ with the same criteria. Females had a higher prevalence of MetS using the harmonized WC cut-off, while males had a higher prevalence of MetS using the WHO BMI cut-off (Table 2). Indian males had a greater prevalence of MetS (47\%) than females (45\%) using BMI as cut-off; however, females had a greater prevalence using WC cut-offs (62\%) compared with males (46\%).

Within the Bengali group, males had a lower prevalence of MetS (50\%) compared with females (52\%) using both WC and BMI measures (45\% and 53\%, respectively). Among the Pakistani group, females had a similar prevalence of MetS using WC compared with males (49\% v. $49 \%$ ).
The percentage of abnormal body composition as assessed by BMI (overweight, obese) differed by ethnic groups. Pakistanis had the highest percentage of obese individuals (36\%) followed by Other SA (29\%), Bengalis (15\%) and Indians (5\%). The percentage of overweight subjects in descending order included: Bengali (42\%), Pakistani (40\%), Other SA (40\%) and Indians (39\%). Bengalis had a lower percentage of subjects who were obese compared with Pakistanis and Indians, yet the highest percentage in the overweight category. The association between BMI status and ethnicity was significant $(P<0 \cdot 001)$. The means for the MetS components of TAG, fasting blood glucose and diastolic blood pressure were not significantly different among the ethnic groups as measured by ANOVA GLM. The only significant differences were between Bengali females and Other SA females for HDLC values.

\section{Metabolic syndrome indicators}

The most prevalent single abnormal indicator was low HDLC and the two most prevalent abnormal indicators were low HDLC and elevated TAG (Table 4). SA Indians presented a different pattern of clustering compared 
Table 4 Frequency of one or more abnormal components for metabolic syndrome, by sex, among South Asian American adults aged 20-68 years from two community health centres in Montgomery and Baltimore County, MD, USA, May 2012-June 2013

\begin{tabular}{llcrr}
\hline Number of abnormal indicators & Most prevalent abnormal component(s) & Overall (\%) & Males (\%) & Females (\%) \\
\hline One† & HDLC & 54 & 44 & 56 \\
Twoł & HDLC + TAG & 29 & 31 & 28 \\
Three§ & HDLC + TAG + GLU & 18 & 20 & 76 \\
Fourll & HDLC + TAG + GLU + WC & 7 & 7 & 8 \\
\hline
\end{tabular}

HDLC, HDL-cholesterol <40 mg/dl (men), $<50 \mathrm{mg} / \mathrm{dl}$ (women); TAG, $\geq 150 \mathrm{mg} / \mathrm{dl}$; GLU, fasting blood glucose $\geq 100 \mathrm{mg} / \mathrm{dl}$; WC, waist circumference $\geq 80 \mathrm{~cm}$ (men), $\geq 90 \mathrm{~cm}$ (women).

†Single most common single abnormal indicator.

¥Two most common abnormal indicators.

$\S$ Three most common abnormal indicators.

IIFour most common abnormal indicators.

with Pakistanis and Bengalis. Low HDLC and elevated blood glucose concentrations were more prevalent in SA Indians.

\section{Determining predictors of metabolic syndrome}

Logistic regression analysis showed that age was the only statistically significant predictor $(\mathrm{OR}=9 \cdot 6$; $95 \%$ CI 1·0, 1·0; $P<0.001)$ of MetS for males in our sample. The odds of developing MetS were higher in older SA than in younger SA. Years in the USA, minutes of exercise, income and education were not statistically significant predictors for males. For females, age and minutes of exercise were the only statistically significant predictors of MetS $(\mathrm{OR}=16.4 ; 95 \%$ CI 1.03, 1.08; $P<0.0001$ and $\mathrm{OR}=0.14$; $95 \%$ CI $1.01,1 \cdot 02 ; P<0.05$, respectively).

\section{Discussion}

While much is known about MetS prevalence and its abnormal indicators in certain groups of Americans ${ }^{(1,26-29)}$, little is known about MetS prevalence in SA Americans. Moreover, most existing studies of SA have focused on Indians $^{(8,14,17,18,30-32)}$, neglecting other groups of SA. The present work represents one of only a few studies to examine MetS prevalence (and the prevalence of abnormal indicators) in the USA in a large sample of SA Americans of different ethnicities and use the newer suggested cut-offs.

In our sample of over 1400 SA American individuals of diverse ethnicity, the prevalence of MetS using the modified harmonized definition $\left(\geq 23.0 \mathrm{~kg} / \mathrm{m}^{2}\right)^{(13)}$ was $49 \%$; $50 \%$ for males and $48 \%$ for females. These prevalences are lower than those recently reported in the USA by Khanna et al. $(77 \%)^{(18)}$, similar to those found by Ramachandran et al. $(41 \%)^{(4)}$ and lower than those observed by Flowers et al. and Dodani et al. $(27 \%)^{(23,33)}$ who also used the harmonized WC cut-offs. Prior to the advent of the new harmonized definition, it had been difficult to compare studies of SA since different researchers used different MetS definitions ${ }^{(1,10,34)}$, various cut-offs $^{(17,35-37)}$ as well as different measures of obesity (WC $v$. waist-to-hip ratio $v$. BMI $)^{(12,14,21,38)}$ for MetS.
Most studies drawn from clinic files data have used weights and heights for the calculation of BMI. The recommendation to use WC rather than $\mathrm{BMI}$ as a measure of obesity has gained momentum recently since the finding that abdominal obesity may be more highly associated with CVD and diabetes ${ }^{(14,39,40)}$ than is overall obesity reflected by BMI. WC is largely absent from older clinic files. Therefore, it has been difficult for researchers to use the harmonized definition based on WC cut-offs. This has compromised our ability to compare studies of MetS prevalence in SA. Herein, we determined an appropriate BMI cut-off value for MetS that gave a similar prevalence of MetS to that using the harmonized WC cut-off. We then applied this BMI cut-off to the clinic file sample ( $n$ 1002). Our analyses revealed that the BMI cut-off value of $23.0 \mathrm{~kg} / \mathrm{m}^{2}$ gave a similar prevalence of MetS as the WC cut-off recommended by the new consensus harmonized definition. Our proposed BMI cut-offs are congruent with the previously recommended BMI cut-offs for SA by Misra et al. ${ }^{(8)}$, who performed ROC curve analysis and suggested $23.0 \mathrm{~kg} / \mathrm{m}^{2}$ for females and $24.0 \mathrm{~kg} / \mathrm{m}^{2}$ for males. Ramachandran et $a l .{ }^{(4)}$ studied South Indians of both sexes who attended hospitals in India found a MetS prevalence of $42 \%$ overall, $36 \%$ for men and $47 \%$ for women ${ }^{(4,41)}$. In 2011, Dodani et $a l .^{(33)}$ conducted a community-based cross-sectional study to ascertain the prevalence of MetS in South Asian immigrants to examine the association between MetS and HDLC function, apolipoprotein (APO1) gene polymorphisms and subclinical coronary artery disease using common carotid intima-media thickness as a surrogate marker. MetS was significantly associated with $\mathrm{BMI} \geq 23.0 \mathrm{~kg} / \mathrm{m}^{2}$ and three $A P O 1 \mathrm{SNP}$ (G2, G3 and G5). The sample contained 35-65-year-olds (seventy-six males, fifty-three females) from Georgia, Kansas and Missouri. Their study used Hindu temples as recruitment sites with a total sample size of 129 first-generation SA Indians. The subjects were categorized not by country but by various language groups (SA, $n$ 33; Guajarati, $n$ 23; Hindi, $n$ 23; Bengali, $n$ 10; Punjabi, $n$ 8; Other, $n$ 4). Using the International Diabetes Federation definition (similar to the harmonized definition), they found the MetS prevalence to be $30 \%$ in SA immigrants without coronary artery disease. 
In that study, Dodani et al. ${ }^{(33)}$ found the prevalence of MetS to be significantly correlated to BMI $>23 \cdot 0 \mathrm{~kg} / \mathrm{m}^{2}$.

We found that the prevalence of MetS differed among the three largest ethnic groups with SA Indian females having the highest prevalence of $62 \%$ and clustered with two abnormal MetS indicators differently, compared with the other SA groups. Similar to Dodani et al. ${ }^{(33)}$, our results showed that Indians had the highest percentage of abnormal HDLC and fasting blood glucose compared with Pakistanis while Bengalis showed a higher prevalence of abnormal HDLC and TAG. These differences existed despite controlling for age, education level and income. The number of years resident in the USA was highest for Indian females and their mean WC was also higher than that of the other ethnic groups, suggesting possible increased adoption of Western eating and activity patterns. Comparisons of females using the harmonized BMI cut-off ( $\geq 23.0 \mathrm{~kg} / \mathrm{m}^{2}$ for overweight) revealed that overweight Indian females had the highest prevalence of MetS (62\%) compared with all other overweight females (50\%). These results suggest that Indian women may have greater metabolic abnormalities at lower BMI levels than do women from other SA groups.

There have been similar suggestions from other studies of SA Indians ${ }^{(41-44)}$. It may also be that at lower BMI levels, abnormal fasting blood glucose increases the risk for the development of MetS in Asian Indians compared with abnormal HDLC and TAG. Although one would surmise that Indians and Pakistani have similar genetic histories, the division of India and Pakistan into separate states for over 60 years and the even longer divergent dietary differences related to their religions may explain the differences found in this and other studies.

Our results suggest that lumping all East Asians and South Asians into one category, i.e. 'all Asian', may not accurately represent the biological diversity inherent in the Asian populations. It may be necessary to disaggregate Asian ethnic groups by country of origin for more comprehensive analyses. Our data, and the findings of others, suggest that the metabolic profiles of Asian Indians may be different enough to warrant further comparisons of the different SA groups.

Our findings from the ROC curve analysis (WC of $89 \mathrm{~cm}$ for women, $79 \mathrm{~cm}$ for men) were largely concordant with the recommended harmonized cut-offs (men $\geq 90 \mathrm{~cm}$, women $\geq 80 \mathrm{~cm}$ ). Unlike some studies that found BMI was not a reliable indicator of MetS in SA Americans ${ }^{(30)}$, our study showed that either BMI (at $23.0 \mathrm{~kg} / \mathrm{m}^{2}$ ) or WC ( $\geq 90 \mathrm{~cm}$ for men, $\geq 80 \mathrm{~cm}$ for women) can be used to determine the prevalence of MetS ${ }^{(8,45,47)}$. However, the important caveat is the BMI cut-off value selected. Our results, and those of others, show that it may not be appropriate to use the BMI cut-offs developed for certain other groups (e.g. European Americans or African Americans) for SA Americans since SA seem to experience metabolic abnormalities at lower BMI and WC cut-off values ${ }^{(19,38,43,47)}$.
The suggestion to use different cut-off values is not new. Other studies have also called for lower BMI cut-offs ${ }^{(30)}$. BMI cut-off values of $25.0 \mathrm{~kg} / \mathrm{m}^{2}$ and $30.0 \mathrm{~kg} / \mathrm{m}^{2}$, derived from European populations, are associated with increased co-morbidities in SA and are clearly too high to use. They underestimate the prevalence of MetS and obfuscate the large numbers of SA who evince metabolic abnormalities at theses higher BMI cut-offs. Some researchers ${ }^{(30)}$ have called for an even lower BMI cut-off $\left(21.0 \mathrm{~kg} / \mathrm{m}^{2}\right)$ for overweight in SA, but this suggestion has failed to gain consensus ${ }^{(21,45,46)}$.

Our sample shows that women had a higher prevalence of MetS (54\%) than men ( $47 \%$ ), a finding contrary to that of Flowers et $a l .{ }^{(23)}$ who found that males had a higher prevalence using the same MetS criteria. Flowers et al. ascribed the sex differences to the protective effect of oestrogen $^{(10)}$. There were no statistically significant differences in the mean WC measures of men and women in our study, but women had a greater prevalence of abnormal WC values and the association between abnormal WC values and sex was statistically significant $(P<0 \cdot 001)$.

Studies on SA in the USA have underestimated the prevalence of MetS. Two studies published in 2010 that used the National Cholesterol Education Program Adult Treatment Panel III (NCEP ATP III) definition of MetS in SA (which employs a BMI cut-off of $>25.0 \mathrm{~kg} / \mathrm{m}^{2}$ ) resulted in an underestimated prevalence in the subjects. The South Asian Health Center (SAHC) ${ }^{(23)}$ in California studied 1445 individuals (1012 men, 433 women) comprised of European and SA Americans, finding $27 \%$ MetS prevalence using the NCEP definition. The birth country was India for majority of their participants ( $n 749)$, and the remaining were from Pakistan ( $n$ 9), Sri Lanka ( $n$ 5) and the USA ( $n$ 40). The participants were recruited through a non-profit organization, (SAHC) programme at El Camino Hospital ${ }^{(23)}$.

Bengali males had the highest prevalence of MetS (50\%) in the present study. Meaningful comparisons for the disaggregated ethnicities in the Other SA male group may be difficult due to small sample size and also combining several ethnic groups together may not be prudent. The sample size was ninety-five subjects for $80 \%$ power. Based on this we had power to discuss differences between Pakistani, Indian and Bengali, but not the individual ethnic differences in the aggregated 'Other SA' group.

Bengali males were significantly better educated than Pakistani males and they also had significantly lower average BMI $\left(26 \cdot 0 \mathrm{~kg} / \mathrm{m}^{2}\right)$ and WC values than Pakistani and Indian males. Bengali males clustered in the highest income bracket earning \$US 45 000-60 000. Interestingly, Bengali males lived in the USA for the shortest time period, suggesting that they may still present disease patterns similar to those in their country of origin, where greater income may equate to money for more energy-dense 
foods. Cultural and dietary analysis may help account for these differences.

We studied the prevalence of one, two, three, four and five abnormal MetS indicators in the overall sample and by ethnic group. Low HDLC was the most prevalent abnormal indicator. The two most prevalent abnormal MetS indicators were low HDLC and high TAG (29\%), the three most prevalent abnormal indicators were low HDLC, high TAG and high fasting blood glucose (18\%), and the four most prevalent abnormal indicators were low HDLC, high TAG, high fasting blood glucose and high WC. Our findings were similar to those seen in other studies of $\mathrm{SA}^{(3,23,48)}$ and showed a greater clustering of abnormal lipid indicators. Other studies suggested a common patterning in SA with insulin resistance in addition to dyslipidaemia characterized by the presence of high TAG and small dense dysfunctional HDLC ${ }^{(33)}$.

Since metabolic abnormalities increase with age, we also analysed MetS across age groups and found that older males and females ( $\geq 60$ years) had a greater prevalence of MetS ( $64 \%$ and $82 \%$, respectively), compared with younger males and females (20-60 years; $50 \%$ and $44 \%$, respectively). However, $\chi^{2}$ analysis showed that the association of MetS with age group was statistically significant only for females $(P<0.005)$. This result may suggest that obesity in elderly subjects ( $\geq 60$ years) was a greater contributor to MetS in females compared with males. Similar results were obtained using a logistic regression model to determine the association between MetS based on age, years resident in the USA, education level, country of origin, minutes of exercise per day and income level. Only age was statistically significant for males $(P<0.001)$ while age and minutes of exercise were significant for females $(P<0.001)$. Education, years resident in the USA and country of origin were not associated with the probability of developing MetS.

Limitations of the present paper are several. First, most of the data were taken from clinic files and based largely on self-reported activity. The study was not representative of all SA ethnic groups, but only those who used the services of the two clinics. The sample sizes were not large enough to analyse smaller groupings of SA Americans, including Sri Lankans, Nepali, etc. The study relied on cross-sectional data and as such cannot show causality between MetS and abnormal MetS indicators. However, the study does suggest the hypothesis that a lower BMI value is needed for SA Americans, which was confirmatory to other studies of SA. Studies that lump SA together may actually obfuscate the real differences in MetS prevalence and causation that may exist among these ethnic groups. Although our sample was a convenience sample, it is one of the largest in number and most diverse in groups of SA studied in the USA.

\section{Conclusion}

The prevalence of MetS in a diverse group of low-income SA at two community health clinics was determined to be $51 \%$ using the most recent consensus harmonized definition. The most accurate BMI cut-off value for detecting MetS that corresponds to the consensus harmonized definition is $23.0 \mathrm{~kg} / \mathrm{m}^{2}$ in SA. Since many clinics which serve the SA community do not collect WC data, we recommend using BMI cut-off of $23.0 \mathrm{~kg} / \mathrm{m}^{2}$ for future epidemiological studies of SA. SA in this sample also had a high prevalence of abnormal HDLC, TAG and blood glucose values. Data from Asian Indians cannot be generalized to all SA; SA are diverse and our data, as well as that those of others, suggest that Asian Indians have a distinct pattern of clustering of blood glucose and TAG. Moreover, Asian Indian females had the highest prevalence of MetS (62\%).

\section{Acknowledgements}

Acknowledgements: The authors wish to thank the two clinics in Maryland where data were collected. Financial support: This research received no specific grant from any funding agency in the public, commercial or not-for-profit sectors. Conflict of interest: None. Authorship: S.A.K. was the lead author who collected, interviewed, entered and analysed the data. R.T.J. provided detailed advice on all parts of the research including the statistics and analysis, and also reviewed and edited the final draft of the paper. Ethics of human subject participation: All patients gave informed consent before participation in the study. Study protocol was approved by the Institutional Review Board of University of Maryland and also by the review boards of the two community centres.

\section{References}

1. Alberti KGMM, Eckel RH, Grundy SM et al. (2009) Harmonizing the metabolic syndrome: a joint interim statement of the International Diabetes Federation Task Force on Epidemiology and Prevention; National Heart, Lung, and Blood Institute; American Heart Association; World Heart Federation; International Atherosclerosis Society; and International Association for the Study of Obesity. Circulation 120, 1640-1645.

2. Kawada T (2014) Predictive ability of metabolic syndrome for incident cardiovascular disease in non-diabetic subjects. Int J Cardiol 172, 255.

3. Singh GK \& Miller BA (2004) Health, life expectancy, and mortality patterns among immigrant populations in the United States. Can J Public Health 95, 114-121.

4. Ramachandran A, Snehalatha C, Satyavani K et al. (2003) Metabolic syndrome in urban Asian Indian adults - a population study using modified ATP III criteria. Diabetes Res Clin Pract 60, 199-204.

5. Misra A \& Khurana L (2008) Obesity and the metabolic syndrome in developing countries. J Clin Endocrinol Metab 93, 11 Suppl. 1, S9-S30. 
6. Gany F, Levy A, Basu P et al. (2012) Culturally tailored health camps and cardiovascular risk among South Asian immigrants. J Health Care Poor Underserved 23, 615-625.

7. Misra A \& Ganda OP (2007) Migration and its impact on adiposity and type 2 diabetes. Nutrition 23, 696-708.

8. Misra A, Pandey RM, Sinha S et al. (2003) Receiver operating characteristics curve analysis of body fat $\&$ body mass index in dyslipidaemic Asian Indians. Indian J Med Res 117, 170-179.

9. Misra A, Chowbey P, Makkar BM et al. (2009) Consensus statement for diagnosis of obesity, abdominal obesity and the metabolic syndrome for Asian Indians and recommendations for physical activity, medical and surgical management. J Assoc Physicians India 57, 163-170.

10. Alberti KGMM, Zimmet P \& Shaw J (2006) Metabolic syndrome - a new world-wide definition. A Consensus Statement from the International Diabetes Federation. Diabet Med 23, 469-480.

11. Ford ES (2005) Prevalence of the metabolic syndrome defined by the International Diabetes Federation among adults in the US. Diabetes Care 28, 2745-2749.

12. Abbasi F, Malhotra D, Mathur A et al. (2012) Body mass index and waist circumference associate to a comparable degree with insulin resistance and related metabolic abnormalities in South Asian women and men. Diab Vasc Dis Res 9, 296-300.

13. WHO Expert Consultation (2004) Appropriate body-mass index for Asian populations and its implications for policy and intervention strategies. Lancet 363, 157-163.

14. Anjana M, Sandeep S, Deepa R et al. (2004) Visceral and central abdominal fat and anthropometry in relation to diabetes in Asian Indians. Diabetes Care 27, 2948-2953.

15. Banerji MA, Faridi N, Atluri R et al. (1999) Body composition, visceral fat, leptin, and insulin resistance in Asian Indian men. I Clin Endocrinol Metab 84, 137-144.

16. Misra A \& Khurana L (2009) The metabolic syndrome in South Asians: epidemiology, determinants, and prevention. Metab Syndr Relat Disord 7, 497-514.

17. Misra A, Wasir JS \& Pandey RM (2005) An evaluation of candidate definitions of the metabolic syndrome in adult Asian Indians. Diabetes Care 28, 398-403.

18. Khanna R, Kapoor A, Kumar S et al. (2013) Metabolic syndrome \& Framingham Risk Score: observations from a coronary angiographic study in Indian patients. Indian J Med Res 137, 295-301.

19. Snehalatha C, Viswanathan V \& Ramachandran A (2003) Cutoff values for normal anthropometric variables in asian Indian adults. Diabetes Care 26, 1380-1384.

20. Tan C-E, Ma S, Wai D et al. (2004) Can we apply the National Cholesterol Education Program Adult Treatment Panel definition of the metabolic syndrome to Asians? Diabetes Care 27, 1182-1186.

21. Vasudevan D, Stotts AL, Mandayam S et al. (2011) Comparison of BMI and anthropometric measures among South Asian Indians using standard and modified criteria. Public Health Nutr 14, 809-816.

22. Schisterman EF, Perkins NJ, Liu A et al. (2005) Optimal cutpoint and its corresponding Youden index to discriminate individuals using pooled blood samples. Epidemiology 16, $73-81$.

23. Flowers E, Molina C, Mathur A et al. (2010) Prevalence of metabolic syndrome in South Asians residing in the United States. Metab Syndr Rel Disord 8, 417-423.

24. Misra R, Patel T, Kotha P et al. (2010) Prevalence of diabetes, metabolic syndrome, and cardiovascular risk factors in US Asian Indians: results from a national study. J Diabetes Complications 24, 145-153.

25. World Health Organization (2000) Obesity: Preventing and Managing the Global Epidemic. Report of a WHO
Consultation WHO Technical Report Series no. 894. Geneva: WHO.

26. Eckel RH, Alberti K, Grundy SM et al. (2010) The metabolic syndrome. Lancet 375, 181-183.

27. Grundy SM, Cleeman JI, Daniels SR et al. (2005) Diagnosis and management of the metabolic syndrome. An American Heart Association/National Heart, Lung, and Blood Institute Scientific Statement. Executive summary. Crit Pathw Cardiol 4, 198-203.

28. Grundy SM, Cleeman JI, Daniels SR et al. (2006) Diagnosis and management of the metabolic syndrome: an American Heart Association/National Heart, Lung, and Blood Institute scientific statement. Curr Opin Cardiol 21, 1-6.

29. Beltrán-Sánchez H, Harhay MO, Harhay MM et al. (2013) Prevalence and trends of metabolic syndrome in the adult US population, 1999-2010. J Am Coll Cardiol 62, 697-703.

30. Dudeja V, Misra A, Pandey RM et al. (2001) BMI does not accurately predict overweight in Asian Indians in northern India. Br J Nutr 86, 105-112.

31. Isharwal S, Misra A, Wasir JS et al. (2009) Diet \& insulin resistance: a review \& Asian Indian perspective. Indian J Med Res 129, 485-499.

32. Gadgil MD, Anderson CA, Kandula NR et al. (2014) Dietary patterns in Asian Indians in the United States: an analysis of the metabolic syndrome and atherosclerosis in South Asians Living in America study. J Acad Nutr Diet 114, 238-243.

33. Dodani S, Henkhaus R, Wick J et al. (2011) Metabolic syndrome in South Asian immigrants: more than low HDL requiring aggressive management. Lipids Health Dis 10, $45-45$.

34. Cameron AJ, Shaw JE \& Zimmet PZ (2004) The metabolic syndrome: prevalence in worldwide populations. Endocrinol Metab Clin North Am 33, 351-375.

35. Balkau B, Charles M-A, Drivsholm T et al. (2002) Frequency of the WHO metabolic syndrome in European cohorts, and an alternative definition of an insulin resistance syndrome. Diabetes Metab 28, 364-376.

36. Carr MC \& Brunzell JD (2004) Abdominal obesity and dyslipidemia in the metabolic syndrome: importance of type 2 diabetes and familial combined hyperlipidemia in coronary artery disease risk. J Clin Endocrinol Metab 89, 2601-2607.

37. Sandeep S, Gokulakrishnan K, Deepa M et al. (2011) Insulin resistance is associated with increased cardiovascular risk in Asian Indians with normal glucose tolerance - the Chennai Urban Rural Epidemiology Study (CURES-66). J Assoc Physicians India 59, 480-484.

38. Lear SA, Toma M, Birmingham CL et al. (2003) Modification of the relationship between simple anthropometric indices and risk factors by ethnic background. Metabolism 52, $1295-1301$.

39. Premanath $\mathrm{M}$, Basavanagowdappa $\mathrm{H}$, Mahesh $\mathrm{M}$ et al. (2014) Correlation of abdominal adiposity with components of metabolic syndrome, anthropometric parameters and insulin resistance, in obese and non obese, diabetics and non diabetics: a cross sectional observational study (Mysore Visceral Adiposity in Diabetes Study). Indian J Endocrinol Metab 18, 676-682.

40. Kanaya AM, Wassel CL, Mathur D et al. (2010) Prevalence and correlates of diabetes in South Asian Indians in the United States: findings from the metabolic syndrome and atherosclerosis in South Asians living in America study and the multi-ethnic study of atherosclerosis. Metab Syndr Relat Disord 8, 157-164.

41. Razak F, Anand SS, Shannon H et al. (2007) Defining obesity cut points in a multiethnic population. Circulation 115, 2111-2118.

42. Misra A, Khurana L, Isharwal S et al. (2009) South Asian diets and insulin resistance. Br J Nutr 101, 465-473. 
43. Jayasinghe SR \& Jayasinghe SH (2009) Variant metabolic risk factor profile leading to premature coronary disease: time to define the syndrome of accelerated atherocoronary metabolic syndrome in Asian Indians. Singapore Med J 50, 949-955.

44. Samaha FF (2007) New international measuring stick for defining obesity in non-Europeans. Circulation 115, 2089-2090.

45. Misra A, Misra R, Wijesuriya M et al. (2007) The metabolic syndrome in South Asians: continuing escalation \& possible solutions. Indian J Med Res 125, $345-354$.
46. Misra A, Wasir JS \& Vikram NK (2005) Action and research are needed for evaluation of optimal definitions of anthropometric parameters and metabolic syndrome for Asians. Diabetes Res Clin Pract 68, 178-179.

47. Chowdhury B, Lantz H \& Sjostrom L (1996) Computed tomography-determined body composition in relation to cardiovascular risk factors in Indian and matched Swedish males. Metabolism 45, 634-644.

48. Gupta M, Doobay AV, Singh N et al. (2002) Risk factors, hospital management and outcomes after acute myocardial infarction in South Asian Canadians and matched control subjects. CMAJ 166, 717-722. 